\title{
Pancreatic Enzyme Response to a Liquid Meal and to Hormonal Stimulation Correlation with Plasma Secretin and Cholecystokinin Levels
}

\author{
Christoph Beglinger, Michael Fried, lan Whitehouse, Jan B. Jansen, Cornelis B. Lamers, and Klaus Gyr \\ Division of Gastroenterology and Department of Research, University Hospital, CH-4031 Basel, Switzerland; \\ Gastrointestinal Hormone Laboratory, St. Radboud Hospital, Nijmegen, The Netherlands
}

\begin{abstract}
Pancreatic trypsin output and plasma secretin and cholecystokinin (CCK) levels were measured in five healthy volunteers to investigate the mechanisms involved in regulating postprandial pancreatic secretion. The pancreas was stimulated by a liquid test meal or by either intravenous secretin (1-82 pmol/ $\mathrm{kg}^{-1}$ per $\mathrm{h}^{-1}$ ) or caerulein, a CCK analogue (2.3-37 pmol/ $\mathrm{kg}^{-1}$ per $h^{-1}$ ), or by a combination of secretin and caerulein. Pancreatic secretion was assessed by a marker perfusion technique (polyethylene glycol [PEG 4000]), plasma secretin, and $\mathrm{CCK}$ by specific radioimmunoassays. Increasing doses of secretin produced increasing bicarbonate output $(P<0.01)$, whereas trypsin was not stimulated over basal. Graded caerulein produced a stepwise increase in trypsin and bicarbonate output $(P<0.01)$. Potentiation occurred for bicarbonate secretion between secretin and caerulein, but not for trypsin output. Postprandial trypsin secretion averaged $29.1 \mathrm{IU} / \mathrm{min}^{-1}$ over $150 \mathrm{~min}$ (equal to $55 \%$ of maximal response to caerulein). The peak trypsin response amounted to $90 \%$ of maximal caerulein. Significant increases of plasma secretin $(P<0.05)$ and $C C K$ $(P<0.01)$ were observed after the meal. Comparison of enzyme and $C C K$ responses to the testmeal or to exogenous caerulein suggested that the amount of $\mathrm{CCK}$ released after the meal could account for the postprandial trypsin secretion. We conclude that $(a)$ the postprandial enzyme response in man is submaximal in comparison to maximal exogenous hormone stimulation; (b) CCK is a major stimulatory mechanism of postprandial trypsin secretion, whereas secretin is not involved; and (c) Potentiation of enzyme secretion is not a regulatory mechanism of the postprandial secretory response.
\end{abstract}

\section{Introduction}

Despite a considerable number of studies on postprandial enzyme secretion in man, many questions remain unanswered. For example, the quantity of enzymes secreted after a meal in comparison to maximal exogenous hormone stimulation is not known (1). Mechanisms regulating postprandial enzyme response are also controversial: hormonal and neural pathways

This work was presented in part at the Annual Meeting of the American Gastroenterological Association, Washington, DC 1983, and appeared in abstract form in Gastroenterology, 1983, 84:1102.

Address correspondence to Dr. Gyr, Division of Gastroenterology, Kantonsspital, CH-4031 Basel, Switzerland.

Received for publication 16 August 1984 and in revised form 7 November 1984.

J. Clin. Invest.

(c) The American Society for Clinical Investigation, Inc.

$0021-9738 / 85 / 05 / 1471 / 06 \$ 1.00$

Volume 75, May 1985, 1471-1476 have been assumed, but have not been investigated with respect to their relative contributions (1). Furthermore, the role of potentiation as a regulating mechanism in the control of pancreatic secretion has to be clarified. While it is accepted that potentiation for pancreatic bicarbonate secretion between pancreatic secretagogues occurs in man $(2,3)$, it is debated if such a mechanism exists for pancreatic enzyme secretion (3$5)$. Finally, the physiological role of cholecystokinin (CCK), ${ }^{1}$ one of the classical pancreatic hormones, has been questioned (6-8). The development of specific and sensitive CCK radioimmunoassay (RIA) systems permitted the study of its physiological role. This prompted us to study in humans the following problems: (1) What is the pancreatic enzyme response to food compared with that of exogenous CCK? (2) Does potentiation of pancreatic enzyme secretion occur between secretin and CCK? (3) How does postprandial CCK-like immunoreactivity (CCKLI) compare with that after exogenous CCK peptides?

\section{Methods}

Volunteers. Five healthy male volunteers, aged 22-26, participated in these studies. The protocol was explained to them and a signed consent was obtained from each subject. The studies were approved by the local Ethical Research Committee.

Experimental design. After an overnight fast, the volunteers swallowed a triple-lumen tube. One lumen was used for continuous perfusion of a nonabsorbable marker (polyethylene glycol = PEG 4000 in $0.154 \mathrm{M}$ saline) and was placed adjacent to the papilla of Vater. A second lumen was employed, $30 \mathrm{~cm}$ distally to the perfusion site, for continuous aspiration of duodenal contents. The third lumen, sited in the antrum, was used for gastric sampling. The final position of the tube was verified by fluoroscopic control. All studies were performed with the subjects in supine position. After the tube was in place, aspiration of gastric and duodenal contents and perfusion of PEG into the duodenum were started simultaneously and continued for 30-60 min until the collections became clear and pH stable. PEG was infused at a rate of $2 \mathrm{ml} / \mathrm{min}^{-1}$ in a concentration of $2 \mathrm{~g} / \mathrm{liter}^{-1}$. On the days when hormones were given, an intravenous infusion of $0.154 \mathrm{M}$ saline was begun before the start of the experiment. The doses of hormones were chosen to produce threshold to maximal secretory responses.

The following tests were started after a 30-min basal period. They were performed on different days and in random order: (a) Synthetic secretin was infused intravenously in graded doses $\left(1-82 \mathrm{pmol} / \mathrm{kg}^{-1}\right.$ per $\mathrm{h}^{-1}$, which was equivalent to $0.012-1$ clinical unit $\left.\mathrm{kg}^{-1} / \mathrm{h}^{-1}\right)$. Each dose was given for $30 \mathrm{~min}$. (b) Synthetic caerulein, a CCK analogue, was infused intravenously in doubling doses $\left(2.3-37 \mathrm{pmol} / \mathrm{kg}^{-1}\right.$ per $\mathrm{h}^{-1}$, which was equivalent to $3.125-50 \mathrm{ng} / \mathrm{kg}^{-1} \mathrm{per} \mathrm{h}^{-1}$ ), each dose for $30 \mathrm{~min}$. (c) Secretin was infused at a dose of $3 \mathrm{pmol} / \mathrm{kg}^{-1}$ per $\mathrm{h}^{-1}$ (equivalent to 0.037 clinical unit $\mathrm{kg}^{-1} / \mathrm{h}^{-1}$ ) for $3 \frac{1}{2} \mathrm{~h}$. Starting from the second hour, synthetic caerulein in the same doses $\left(2.3-37 \mathrm{pmol} / \mathrm{kg}^{-1}\right.$ per $\mathrm{h}^{-1}$ ) was infused simultaneously with secretin, each dose for 30

1. Abbreviations used in this paper: CCK, cholecystokinin; CCKLI, CCK-like immunoreactivity; PEG, polyethylene glycol. 
min. (d) After the basal period, the volunteers drank a liquid meal within $3 \mathrm{~min}$. According to the manufacturer's analysis, the meal (400 $\mathrm{ml}$ ) consisted of $21 \mathrm{~g}$ protein, $16.6 \mathrm{~g}$ fat, and $78 \mathrm{~g}$ carbohydrates (mixture of one bag Meritene plus one bag Edarene in $400 \mathrm{ml}$ of water). It had an osmolality of $550 \mathrm{mosmol} / \mathrm{liter}^{-1}$ and a $\mathrm{pH}$ of 5.9 . The total caloric value was $2,300 \mathrm{~kJ}$, which was equivalent to 565 kcal. In this study, gastric aspiration was discontinued after the basal period, but duodenal perfusion of PEG and aspiration continued.

In studies where exogenous hormones were given, blood samples for secretin and cholecystokinin RIA were obtained in duplicates at the baseline and at the end of each dose of each stimulant. During the meal study, blood was drawn at baseline and at 15-min intervals for 3 h. Blood was collected in ice-chilled tubes that contained $150 \mu \mathrm{g}$ EDTA and 5,000 KIU aprotinin per $5 \mathrm{ml}$ blood. Samples were immediately centrifuged at $4^{\circ} \mathrm{C}$ and the plasma stored at $-20^{\circ} \mathrm{C}$ until it was assayed.

Materials. Synthetic porcine secretin was a kind gift of Dr. Gillessen, F. Hoffmann-LaRoche \& Co., Ltd., Basel, Switzerland. Synthetic caerulein was purchased from Farmitalia, Milan, Italy. Meritene and Edarene were kind gifts of Wander AG, Berne, Switzerland.

Determinations. Volume was measured to the next $0.1 \mathrm{ml}$; bicarbonate concentration of duodenal juice was determined by the backtitration method (9); and trypsin concentration was measured by the method of Wiggins using $N$-benzoyl-L-arginine-ethylester-hydrochloride as substrate (10). PEG concentration was determined turbidimetrically by a modified method of Hydén (11).

Plasma secretin RIA. Plasma secretin was measured as previously described in detail (12). In short, the secretin antibody was raised in rabbits. Synthetic secretin was used as standard and tracer. Secretin was labeled with a ${ }^{125}$ I by a modified lactoperoxidase method (12). Labeled secretin was purified on a SP Sephadex C25 column. The specific radioactivity from different iodinations ranged from 400 to $800 \mu \mathrm{Ci} / \mathrm{nmol}^{-1}$. Plasma was treated by ethanol extraction. The extraction recovery of plasma samples was $92 \pm 4 \%$ when $10 \mathrm{pg}$ secretinpentacitrate was added per milliliter charcoal-stripped human plasma. The standards of synthetic secretin were prepared by adding $400 \mu \mathrm{l}$ of assay buffer with $0-30 \mathrm{fmol}$ of secretin to tubes containing dried ethanol extracts of charcoal-stripped human plasma. The sensitivity of the assay was $0.3 \pm 0.02 \mathrm{pmol} / \mathrm{liter}^{-1}$ plasma. No significant crossreactivity was observed with vasoactive intestinal polypeptide, gastric inhibitory polypeptide, and pancreatic glucagon. The intraassay and interassay variation was 11.9 and $15.5 \%$, respectively, at $3.3 \mathrm{pmol} /$ liter $^{-1}$.

Plasma CCK RIA. Plasma CCK concentrations were estimated by a recently published specific RIA (7, 13-15). Antibody T204 binds to all carboxyl-terminal CCK peptides containing the sulfated tyrosine. The antibody shows $<2 \%$ cross-reactivity to sulfated gastrins and does not bind to unsulfated forms of gastrin $(7,13-15)$. It does not crossreact with structurally unrelated gastrointestinal peptides as insulin, glucagon, secretin, pancreatic polypeptide, bombesin, or neurotensin. CCK33 coupled to ${ }^{125}$ I-hydroxyphenylpropionic acid succinimide ester (Bolton-Hunter reagent) was used as label. The specific radioactivity ranged from 260 to $485 \mu \mathrm{Ci} / \mu \mathrm{g}^{-1}(n=8)$. 99\% pure cholecystokinin 33 in the meal study and synthetic caerulein in the caerulein infusion study were used as standards. Dilution curves of $99 \%$ pure CCK and synthetic caerulein were parallel (Fig. 1). A two-step incubation procedure was used. Separation between free and antibody-bound hormone was performed by a charcoal method. The $50 \%$ inhibition dose was $3.3 \mathrm{pmol} / \mathrm{liter}^{-1}$. All plasma samples were treated by an ethanol extraction procedure. The extraction recovery of plasma samples was $85 \pm 2 \%$ when CCK33 and $90 \pm 2 \%$ when sulfated CCK 8 was added to hormone-free plasma. The intraassay and interassay variation was 8.4 and $11.3 \%$, respectively, at $2.6 \mathrm{pmol} / \mathrm{liter}^{-1}$.

Statistics and calculations. In dose-response studies, values from the last two 10-min periods during basal collections, background infusions, and each dose of stimulant were averaged and used to calculate outputs per minute for bicarbonate (micromoles) and trypsin (international units). Incremental responses were obtained by subtracting

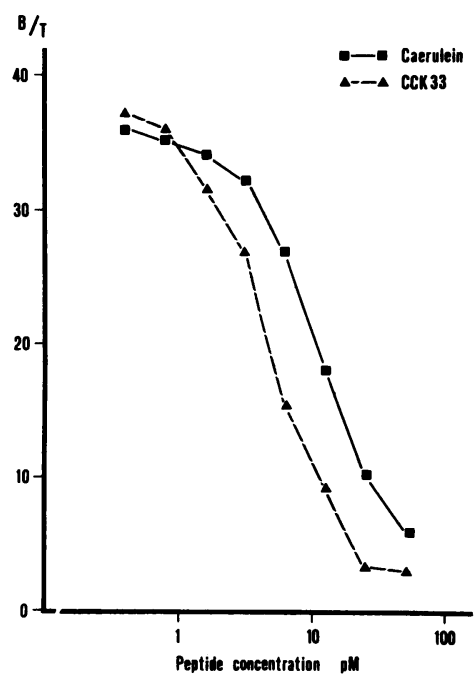

Figure 1. Inhibition curves for natural porcine CCK33 and synthetic caerulein against binding of ${ }^{125} \mathrm{I}-\mathrm{la}$ beled natural CCK33 by antibody T204. Ratio of bound to total label is plotted against peptide concentration (pM in assay tube).

the basal pancreatic secretion in dose-response studies with single stimulants. In all the experiments where combinations of secretin and caerulein were administered, the response to the background agent alone was substracted from all subsequent responses to give the incremental secretory data that are reported. The response to secretin alone (S), as an example, was subtracted from the subsequent responses to secretin plus caerulein $(S+C)$. If $\Delta(S+C)$ was greater than caerulein alone minus basal, potentiation between the two stimulants was assumed to exist. We performed statistical tests on the calculated indices of secretion. First we compared the responses to the lowest and to the maximal dose of caerulein given alone or with a background of secretin. Secondly, we calculated the cumulative incremental responses to all doses of caerulein given alone or with a secretin background (5, 16). In the meal study and for all plasma hormone concentrations, values are given as mean \pm SEM. $t$ test for paired samples was used to analyze data for statistical significance of differences between means. Differences with a $P$ value of $<0.05$ were considered to be significant.

The PEG solution served as nonabsorbable marker to calculate the duodenal volume for a given period by the following equation (3): $V$ $=(\mathrm{F} \times[\mathrm{PEG}]$ perf $\times 10) /(\mathrm{PEG}$ meas $)$, where $\mathrm{V}$ is calculated duodenal volume ( $\left.\mathrm{ml} / 10 \mathrm{~min}^{-1}\right) ; \mathrm{F}$ is the flow rate of PEG solution perfused (2 $\mathrm{ml} / \mathrm{min}^{-1}$ ); PEG perf is the concentration of PEG in the perfusate, and PEG meas is the concentration of PEG in the duodenal juice collected for $10 \mathrm{~min}$. The recovery of the duodenal marker (PEG 4000 ) averaged $67 \%$ (range $57-71 \%$ ). The average percentage of PEG 4000 recovered from the stomach was $5 \%$ (range $0-9 \%$ ).

\section{Results}

Pancreatic secretion to hormonal stimulants. As expected, the infusion of graded doses of secretin produced increasing stimulation of pancreatic bicarbonate secretion. Even when given alone, the lowest dose of secretin $\left(1 \mathrm{pmol} / \mathrm{kg}^{-1}\right.$ per $\left.\mathrm{h}^{-1}\right)$ caused a statistically significant $(P<0.05)$ increase of bicarbonate output over basal values (the incremental bicarbonate response was $10 \pm 3 \mu \mathrm{mol} / \mathrm{min}^{-1}$ ). The highest dose of secretin ( $82 \mathrm{pmol} /$ $\mathrm{kg}^{-1}$ per $\mathrm{h}^{-1}$ ) did not produce maximal bicarbonate secretion. Infusion of secretin produced small increases of trypsin output which were not statistically significant from basal values. Basal pancreatic bicarbonate secretion averaged $23 \pm 7 \mu \mathrm{mol} / \mathrm{min}^{-1}$, whereas basal trypsin output amounted to $15 \pm 6 \mathrm{IU} / \mathrm{min}^{-1}$.

Given alone, the lowest dose of caerulein did not increase bicarbonate secretion above basal levels (basal trypsin output $10 \pm 4 \mathrm{IU} / \mathrm{min}^{-1}$; basal bicarbonate output $\left.16 \pm 3 \mu \mathrm{mol} / \mathrm{min}^{-1}\right)$; it did, however, significantly $(P<0.05)$ stimulate trypsin output 
Table I. Maximal Observed and Cumulative Incremental Secretory Responses to Stimulants Given Alone and in Combination

\begin{tabular}{lccccc}
\hline & \multicolumn{2}{c}{ Bicarbonate output $\left(\mu \mathrm{mol}_{\mathbf{m}} \mathrm{min}^{-1}\right)$} & & \multicolumn{2}{c}{ Trypsin output $(I U) \mathrm{min}^{-1}$} \\
\cline { 2 - 5 } & Maximal observed & Cumulative & & Maximal observed & Cumulative \\
\hline Graded caerulein alone & $74.9 \pm 12.1$ & $200.7 \pm 38.8$ & $53.9 \pm 8.2$ & $136.8 \pm 14.4$ \\
Graded caerulein plus secretin & $375.1 \pm 43.3^{*}$ & $982.8 \pm 133.7^{*}$ & $46.7 \pm 5.8$ & $128.6 \pm 19.0$
\end{tabular}

For caerulein given alone, basal values were substracted from individual values; for combinations (caerulein plus secretin), the responses to the secretin background were substracted. The incremental values were used to calculate values for group mean \pm SEM shown above $(n=5)$. ${ }^{*} P$ $<0.01$.

(incremental values: $5.4 \pm 1.3 \mathrm{IU} / \mathrm{min}^{-1}$ ). The maximal observed typsin output was achieved with $18.5 \mathrm{pmol} / \mathrm{kg}^{-1}$ per $\mathrm{h}^{-1}$, whereas $37 \mathrm{pmol} / \mathrm{kg}^{-1}$ per $\mathrm{h}^{-1}$ of caerulein was clearly supramaximal and caused submaximal enzyme release. Doubling doses of caerulein induced a small, but significant $(P$ $<0.01$ ) dose-dependent increase of bicarbonate output.

A background infusion of secretin, $3 \mathrm{pmol} / \mathrm{kg}^{-1}$ per h $\mathrm{h}^{-1}$, significantly potentiated $(P<0.02)$ the bicarbonate response to the lowest dose of caerulein. There was also marked potentiation of the maximal observed $(P<0.05)$ and cumulative $(P<0.01)$ incremental bicarbonate responses after combined stimulation with caerulein and secretin compared with control experiments. By contrast, no potentiation for enzyme secretion was observed: background secretin infusion did not significantly change either the maximal observed nor cumulative incremental trypsin responses to graded doses of caerulein (Table I). Basal bicarbonate output was $21 \pm 4 \mu \mathrm{mol} / \mathrm{min}^{-1}$ and trypsin output $12 \pm 3 \mathrm{IU} / \mathrm{min}^{-1}$.

Pancreatic enzyme response to testmeal. Trypsin output increased shortly after taking the meal (Fig. 2), reaching an approximate steady state after 30 to $40 \mathrm{~min}$. The steady state persisted more or less until the end of the experiment. The peak enzyme response was calculated from the three highest consecutive 10-min periods, disregarding the first $30 \mathrm{~min}$ of the test to exclude washout secretion (15). The incremental peak trypsin output was therefore $48.6 \pm 8.0 \mathrm{IU} / \mathrm{min}^{-1}$. The cumulative trypsin output over $3 \mathrm{~h}$ was $4.8 \mathrm{KIU}$.

Comparison of pancreatic enzyme response to food and caerulein stimulation. The peak trypsin output to the meal $\left(48.6 \pm 8.0 \mathrm{IU} / \mathrm{min}^{-1}\right)$ was $90 \%$ (range $65-128 \%$ ) of the maximal trypsin response to caerulein. Over a 30 - to 180 -min period,

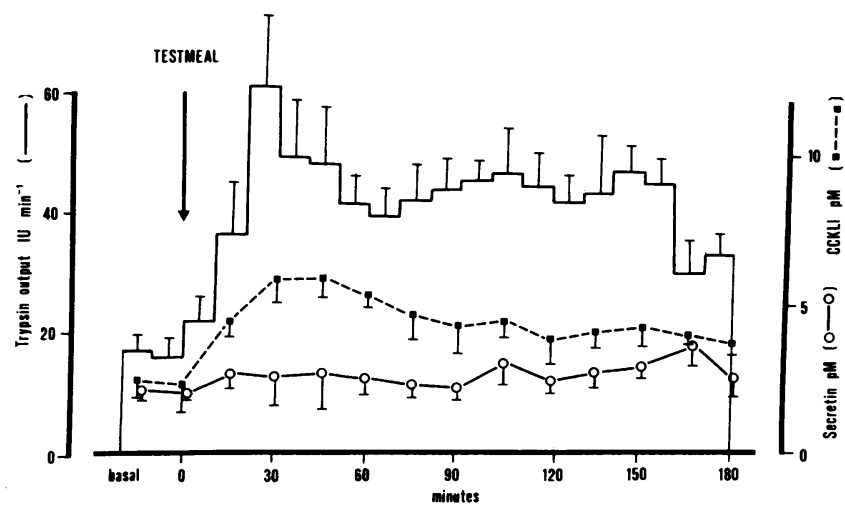

Figure 2. Effect of a liquid test meal on trypsin output and plasma CCK and secretin concentrations in five volunteers. Mean \pm SEM. Basal trypsin output: $16 \pm 4 \mathrm{IU} / \mathrm{min}^{-1}$. Basal plasma secretin: $2.4 \pm 0.3$ $\mathrm{pmol} /$ liter $^{-1}$; basal plasma CCK: $2.3 \pm 0.5 \mathrm{pmol} / \mathrm{liter}^{-1}$. the trypsin output with the meal averaged $29.4 \pm 2.1 \mathrm{IU} / \mathrm{min}^{-1}$, which is $55 \%$ of maximal to caerulein.

Plasma secretin concentrations. Fasting plasma secretin concentrations were comparable in the different experiments $\left(2.3 \pm 0.2 \mathrm{pmol} / \mathrm{liter}^{-1}\right.$ plasma). Exogenous secretin produced a dose-dependent increase in plasma secretin concentrations (Table II). The correlation between secretin doses infused and plasma secretin levels was: $y=1.09+0.47 \times(r=0.978, P$ $<0.01) .1 \mathrm{pmol} / \mathrm{kg}^{-1}$ per $\mathrm{h}^{-1}$ of secretin resulted in a small but significant $(P<0.05)$ elevation in plasma secretin levels (mean incremental increase: $0.8 \pm 0.3 \mathrm{pmol} /$ liter $^{-1}$ ). The plasma levels were not influenced by intravenous caerulein or addition of caerulein to intravenous secretin infusion (data not shown).

In the postprandial period, secretin concentration changed significantly $(P<0.05)$ in each volunteer. However, no sustained increase of plasma secretin was observed (Fig. 2), but secretin release appeared to occur in spikes. The maximal postprandial secretin release over basal levels was $1.3 \pm 0.3$ pmol/liter ${ }^{-1}(P<0.01)$, whereas the cumulative incremental postprandial secretin release amounted to $4.5 \pm 1.5 \mathrm{pmol} / \mathrm{liter}^{-1}$ $(P<0.05)$.

Plasma CCK concentrations. Fasting plasma CCK levels were comparable in the different experiments (mean: $2.4 \pm 0.5$ $\mathrm{pmol} / \mathrm{liter}^{-1}$ ). Exogenous caerulein produced a dose-dependent increase in plasma CCKLI, which was significant for the second and all subsequent doses (Table III). An excellent correlation between caerulein doses infused and plasma caerulein levels was obtained: $y=2.02+0.58 x, r=0.980, P$ $<0.01$.

After the testmeal, plasma CCK increased rapidly in each volunteer $(P<0.05)$. The peak response over basal values was

Table II. Incremental Plasma Secretin

Concentration* in Response to Graded Doses of Exogenous Secretin in Five Healthy Volunteers

\begin{tabular}{cl}
\hline Dose of secretin & $\begin{array}{l}\text { Increment in plasma } \\
\text { secretin levels }\end{array}$ \\
\hline$p m o l / \mathrm{kg}^{-1} / h^{-1}$ & $p M$ \\
1 & $0.8 \pm 0.3$ \\
3 & $2.2 \pm 0.2$ \\
9 & $5.0 \pm 1.4$ \\
27 & $17.6 \pm 2.4$ \\
82 & $37.8 \pm 6.4$
\end{tabular}

For each volunteer, the incremental value (the increase over basal) represents the average of two plasma samples taken at the end of each dose. Basal values were $2.2 \pm 0.4 \mathrm{pM}$.

* pM. 
Table III. Increment in Plasma Caerulein Concentration in Response to Graded Doses of Exogenous Caerulein: Comparison with Plasma CCK Response to a Meal

\begin{tabular}{lc}
\hline Dose of caerulein & $\begin{array}{l}\text { Increment in } \\
\text { plasma CCKLI }\end{array}$ \\
\hline$p m o l / \mathrm{kg}^{-1} / h^{-1}$ & $p M$ \\
2.3 & $0.5 \pm 0.3$ \\
4.6 & $1.5 \pm 0.2$ \\
9.2 & $2.6 \pm 0.3$ \\
18.5 & $6.1 \pm 1.2$ \\
37.0 & $20.8 \pm 4.6$ \\
Meal & $2.4 \pm 0.4$
\end{tabular}

For each volunteer, the incremental value (the increase over basal) represents the average of two plasma samples taken at the end of each dose. Basal values are calculated from the average of two samples in each test. The mean response represents the mean of 12 samples drawn during $180 \mathrm{~min}$ after feeding; the individual means were used to calculate a group mean and SE that is shown $(n=5)$.

3.7 $\pm 0.4 \mathrm{pmol} / \mathrm{liter}^{-1}$ and occurred between the 15 th and 45 th min after ingestion of the meal. CCK levels remained elevated until the end of the experiment, although they had a tendency to decline (Fig. 2). The cumulative incremental CCK response

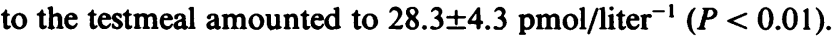

\section{Discussion}

It is generally accepted that the intestinal phase of the pancreatic secretory response to food is primarily mediated by neural and hormonal pathways that arise from the duodenal mucosa and are activated by digestive products. While the mechanisms responsible for pancreatic bicarbonate secretion have recently been elucidated to a considerable extent (17-22), those regulating the postprandial enzyme response have still to be defined. The role of cholecystokinin, one of the classical postulated hormonal regulators of pancreatic enzyme secretion, continues to be puzzlesome, however, despite the specific and sensitive RIA systems recently described $(7,8,13-15,23-27)$. Their use has so far not been widespread enough to provide more than a cursory view of the physiology of CCK, at best. Another point that requires clarification is the role of interactions between stimulants in the regulation of pancreatic secretory response. It has been proposed that small amounts of secretin and of CCK greatly potentiate each other's action on the pancreas, so that the pancreas secretes larger amounts of both bicarbonate and enzymes than could be expected from adding the single effects of each hormone $(1,28)$. Such a potentiation with stimulants of pancreatic bicarbonate secretion has been established in man $(2,3)$, but remains controversial with regard to secretagogues of pancreatic enzyme secretion. Most evidence in favor of potentiation for enzyme secretion results from observations of in vitro studies where combinations of secretin and CCK produced potentiated amylase secretion $(29,30)$.

The present study confirms $(2,3)$ the existence of potentiation of pancreatic bicarbonate secretion in man between secretin and CCK analogues given intravenously in physiological doses. It shows in addition a striking lack of potentiation of pancreatic enzyme secretion by combined stimulation with secretin and caerulein. The lack of potentiation of pancreatic enzyme secretion in man and also in dogs as recently reported from our laboratory $(5,12)$ is in favor of the hypothesis $(5)$ that potentiation of enzyme secretion occurs only in those species in which secretin alone can stimulate enzyme release. We conclude from this and previous work that potentiation of enzyme secretion with these stimulants is not an important regulatory mechanism in man. It challenges Grossman's assumption that secretin and CCK each potentiate each other's primary action (28).

A further controversy addresses the amount of enzyme secreted after a meal. Our results suggest that the postprandial enzyme response to a liquid meal (reaching an average peak trypsin output of $90 \%$ of maximal caerulein-stimulated trypsin secretion) is considerably higher than so far assumed. This is in contrast to Henriksen's quoted results observed in dogs (31), where digestive enzyme secretion was found to be surprisingly low, being in the order of $20 \%$ of maximal CCKstimulated output. Similar observations have been reported by Sarles's group (32). The difference cannot be explained by a simple species difference, since we recently found submaximal enzyme secretion in dogs equipped with chronic duodenal Herrera fistulas (peak protein response $=94 \%$ of maximal CCK-stimulated output in six dogs; Beglinger, C., and K. Gyr, unpublished data). Methodological problems may have contributed to the discrepancies, since two different dog models were used (Herrera type fistula vs. Thomas fistula). Indeed, several observations of other investigators support our findings: Malagelada and co-workers (18) report that the peak postprandial trypsin output after a solid liquid or a homogenized meal resembled those in response to high doses of intravenous CCK in man. Similar pancreatic enzyme responses have been described during intraduodenal perfusion with high concentrations of fatty acids (33) or Lundh-type liquid formula meals (34). No comparison was made with exogenous CCK in these studies. MacGregor and co-workers (35) reported that a liquid testmeal was itself a stimulus, with $\sim 60 \%$ of the efficacy of exogenous CCK. They did, however, not specify if this value refers to the mean secretory trypsin response or to the peak output. Assuming the first, our results would be quite similar to MacGregor's (mean trypsin output from 30 to $150 \mathrm{~min}$ $=55 \%$ of maximal), which suggests that the pancreas is very similar to the stomach: both secrete at submaximal rates in response to food (36).

The plasma hormone data from this study provide new insight into the regulation of pancreatic enzyme secretion. Ingestion of the testmeal induced significant increases in plasma CCK and pancreatic trypsin secretion. The mean postprandial increase in plasma CCK was $2.4 \mathrm{pmol} / \mathrm{liter}^{-1}$, while the mean postprandial trypsin response was $29.4 \mathrm{IU} /$ $\mathrm{min}^{-1}$. When a similar increase in plasma CCKLI $(2.6 \mathrm{pmol} /$ liter ${ }^{-1}$ ) was produced by infusion of $9.2 \mathrm{pmol} / \mathrm{kg}^{-1}$ per $\mathrm{h}^{-1}$ caerulein, the pancreatic trypsin response $\left(31 \pm 3 \mathrm{IU} / \mathrm{min}^{-1}\right)$ was very similar to that found after the meal. These results suggest that the release of CCK could account for the postprandial trypsin secretion after this specific testmeal. This finding is in agreement with a recent study published in abstract form, which indicates that the release of CCK can exclusively account for the enzyme secretion in response to intestinal oleate in the dog (37). It can be argued that caerulein is a synthetic CCK peptide that is not present in plasma under 
physiological circumstances. However, equimolar doses of CCK33 should produce similar results, as we have shown recently that on a molar basis caerulein and CCK33 are equipotent in stimulating enzyme secretion $(38,39)$. Nevertheless, considering the interplay between stimulatory and inhibitory mechanisms under physiological conditions, caution is indicated with regard to conclusions based on analogy between hormone plasma levels measured after a meal and those measured during experimental hormone infusion.

It was further indicated in the present study that the small amounts of secretin released in response to the meal do not contribute to the postprandial pancreatic enzyme secretion, since infusion of secretin does neither stimulate enzyme secretion nor potentiate the effect of CCK on enzyme output from the pancreas. On the other hand, low doses of exogenous secretin can stimulate pancreatic bicarbonate secretion with concomitant increases in plasma secretin, which confirms a previous study (19). Comparable secretin concentrations were detected postprandially, but no data can be given concerning pancreatic fluid or bicarbonate secretion owing to the technical problems involved in specifically measuring pancreatic bicarbonate secretion in response to food in man.

\section{Acknowledgments}

We thank Mrs. Carita Frei for editorial assistance and for typing the manuscript, and Mrs. Luisa Jeker for expert technical assistance. (This study was supported by grant 3.918 .082 from the Swiss National Science Foundation and grant 13-37.32 from the Netherlands Foundation for Medical Research FUNGO.

\section{References}

1. Meyer, J. H. 1981. Control of pancreatic exocrine secretion. In Physiology of Gastrointestinal Tract. L. R. Johnson, editor. Raven Press, New York. 821-829.

2. Wormsley, K. G. 1969. A comparison of the response to secretin, pancreozymin and a combination of these hormones, in man. Scand. J. Gastroenterol. 4:413-417.

3. You, C. H., J. M. Rominger, and W. Y. Chey. 1983. Potentiation effect of cholecystokinin-octapeptide on pancreatic bicarbonate secretion stimulated by a physiologic dose of secretin in humans. Gastroenterology. 85:40-45.

4. Csendes, A., J. I. Isenberg, and M. I. Grossman. 1971. Pancreatic protein secretion in response to secretin plus C-terminal octapeptide of cholecystokinin. Gastroenterology. 60:770.

5. Beglinger, C., M. I. Grossman, and T. E. Solomon. 1984. Interaction between stimulants of exocrine pancreatic secretion in dogs. Am. J. Physiol. 246:G173-G179.

6. Valenzuela, J., C. B. Lamers, I. M. Modlin, and J. H. Walsh. 1983. Cholinergic component in the human pancreatic secretory response to intraintestinal oleate. Gut. 24:807-811.

7. Jansen, J. B. M. J., and C. B. H. W. Lamers. 1983. Radioimmunoassay of cholecystokinin in human tissue and plasma. Clin. Chim. Acta. 131:305-316.

8. Himeno, S., S. Tarui, S. Kanayama, T. Kuroshima, Y. Shinomura, C. Hayashi, K. Tateishi, K. Imagawa, E. Hashimura, and T. Hamaoka. 1983. Plasma cholecystokinin responses after ingestion of liquid meal and intraduodenal infusion of fat, amino acids, or hydrochloric acid in man: analysis with region specific radioimmunoassay. Am. J. Gastroenterol. 78:703-707.

9. Lagerlöf, H. O. 1942. Pancreatic function and pancreatic disease studied by means of secretin. Acta Med. Scand. Suppl. 128:1-289.
10. Wiggins, H. S. 1967. Simple method for estimating trypsin. Gut. 8:415-416.

11. Hydén, S. 1956. A turbidimetric method for the determination of higher polyethylene glycols in biological materials. Kungl. Lantbrukshögsk. Ann. 22:139-145.

12. Gyr, K., C. Beglinger, M. Fried, U. Grötzinger, L. Kayasseh, G. A. Stalder, and J. Girard. 1984. Plasma secretin and pancreatic response to various stimulants including a meal. Am. J. Physiol. 246: G535-G542.

13. Jansen, J. B. M. J., and C. B. H. W. Lamers. 1983. Radioimmunoassay of cholecystokinin: production and evaluation of antibodies. J. Clin. Chem. Clin. Biochem. 21:387-394.

14. Jansen, J. B. M. J., and C. B. H. W. Lamers. 1983. Molecular forms of cholecystokinin in human plasma during infusion of bombesin. Life Sci. 33:2197-2205.

15. Hopman, W. P. M., J. B. M. J. Jansen, and C. B. H. W. Lamers. 1984. Effect of atropine on the plasma cholecystokinin response to intraduodenal fat in man. Digestion. 29:19-25.

16. Elashoff, J. D. 1981. Down with multiple t-tests! Gastroenterology. 80:615-620.

17. Moore, E. W., H. J. Verine, and M. I. Grossman. 1979. Pancreatic bicarbonate response to a meal. Acta Hepato-Gastroenterol. 26:30-36.

18. Malagelada, J. R., V. L. W. Go, and W. H. J. Summerskill. 1979. Different gastric, pancreatic, and biliary responses to solid-liquid or homogenized meals. Dig. Dis. Sci. 24:101-110.

19. Schaffalitzky de Muckadell, O. B., and J. Fahrenkrug. 1978. Secretion pattern of secretin in man: regulation by gastric acid. Gut. 19:812-818.

20. Chey, W. Y., Y. H. Lee, J. G. Hendricks, R. A. Rhodes, and H. H. Tai. 1978. Plasma secretin concentrations in fasting and postprandial state in man. Digestive Diseases. 23:981-988.

21. Pelletier, M. J., J. A. P. Chayvialle, and Y. Minaire. 1978. Uneven and transient secretin release after a liquid test meal. Gastroenterology. 75:1124-1132.

22. Chey, W. Y., M. S. Kim, K. Y. Lee, and T. M. Chang. 1979. Effect of rabbit antisecretin serum on postprandial pancreatic secretion in dogs. Gastroenterology. 77:1268-1275.

23. Byrnes, D. J., L. Henderson, T. Borody, and J. F. Rehfeld. 1981. Radioimmunoassay of cholecystokinin in human plasma. Clin. Chim. Acta. 111:81-89.

24. Calam, J., A. Ellis, and G. J. Dockray. 1982. Identification and measurement of molecular variants of cholecystokinin in duodenal mucosa and plasma. J. Clin. Invest. 69:218-225.

25. Walsh, J. H., C. B. Lamers, and J. E. Valenzuela. 1982. Cholecystokinin-octapeptidelike immunoreactivity in human plasma. Gastroenterology. 82:438-444.

26. Lilja, P., C. J. Fagan, I. Wiener, K. Inoue, L. C. Watson, P. L. Rayford, and J. C. Thompson. 1982. Infusion of pure cholecystokinin in humans. Correlation between plasma concentrations of cholecystokinin and gallbladder size. Gastroenterology. 83:256-261.

27. Chang, T. M., and W. Y. Chey. 1983. Radioimmunoassay of cholecystokinin. Dig. Dis. Sci. 28:456-468.

28. Grossman, M. I. 1971. Control of pancreatic secretion. In The Exocrine Pancreas. I. T. Beck and D. G. Sinclair, editors. Churchill Livingstone, London. 59-73.

29. Collen, M. J., V. E. Sutliff, G. Z. Pan, and J. D. Gardner. 1982. Postreceptor modulation of action of VIP and secretin on pancreatic enzyme secretion by secretagogues that mobilize cellular calcium. Am. J. Physiol. 242:G423-G428.

30. Gardner, J. D., and M. J. Jackson. 1977. Regulation of amylase release from dispersed pancreatic acinar cells. J. Physiol. (Lond.) 270: 439-454.

31. Henriksen, F. W., and H. Worning. 1969. External pancreatic response to food and its relation to the maximal secretory capacity in dogs. Gut. 10:209-214. 
32. Roblès Diaz, G., M. A. Devaux, C. D. Johnson, Z. Adrich, and H. Sarles. 1982. Physiological conditions for the study of basal and meal stimulated exocrine pancreatic secretion in the dog. Absence of feedback inhibition of basal secretion. Can. J. Physiol. Pharmacol. 60:1287-1295.

33. Malagelada, J. R., V. L. W. Go, E. P. DiMagno, and W. H. J. Summerskill. 1973. Interactions between intraluminal bile acids and digestive products on pancreatic and gallbladder function. J. Clin. Invest. 52:2160-2165.

34. Brunner, H., T. C. Northfield, A. F. Hofmann, V. L. W. Go, and W. H. J. Summerskill. 1974. Gastric emptying and secretion of bile acids, cholesterol, and pancreatic enzymes during digestion. Duodenal perfusion studies in healthy subjects. Mayo Clin. Proc. 49:851860.

35. MacGregor, I., J. Parent, and J. H. Meyer. 1977. Gastric emptying of liquid meals and pancreatic and biliary secretion after subtotal gastrectomy or truncal vagotomy and pyloroplasty in man. Gastroenterology. 72:195-205.

36. Lam, S. K., J. I. Isenberg, M. I. Grossman, W. H. Lane, and J. H. Walsh. 1980. Gastric acid secretion is abnormally sensitive to endogenous gastrin released after peptone test meals in duodenal ulcer patients. J. Clin. Invest. 65:555-562.

37. Konturek, S. J., W. Bielanski, J. Tasler, J. Bilski, J. Jansen, A. de Jong, and C. Lamers. 1984. Release of secretin, CCK and PP by regional perfusion of intestine with $\mathrm{HCl}$ and oleate. Gastroenterology. 86:1140.

38. Beglinger, C., T. E. Solomon, K. Gyr, L. Moroder, and E. Wuensch. 1984. Exocrine pancreatic secretion in response to a new CCK analog, CCK33, and caerulein in dogs. Regul. Pept. 8:291-296.

39. Solomon, T. E., T. Yamada, J. Elashoff, J. G. Wood, and C. Beglinger. 1984. Bioactivity of cholecystokinin analogs: CCK8 is not more potent than CCK33. Am. J. Physiol. 247:G105-G111. 